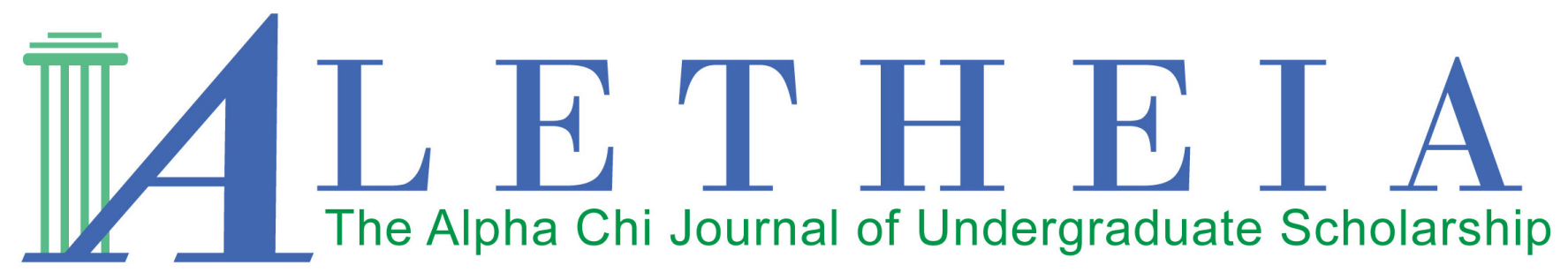

Volume 6 | Issue 2 | 2021

\title{
Monolingual and Bilingual College Students' Performance on English and Artificial Stroop Tests
}

\author{
Elise N. Gray \\ Texas Lutheran University \\ Texas Alpha Delta Chapter
}

Vol. 6(2), 2021

Title: Monolingual and Bilingual College Students' Performance on English and Artificial Stroop Tests

DOI: $10.21081 / \mathrm{ax} 0306$

ISSN: 2381-800X

Keywords: Bilingual cognitive advantage, inhibition, Stroop effect, language learning, and multilingualism This work is licensed under a Creative Commons Attribution 4.0 International License.

Author contact information is available from tlindblom@alphachihonor.org or kvosevich@alphachihonor.org

\section{Aletheia-The Alpha Chi Journal of Undergraduate Scholarship}

- This publication is an online, peer-reviewed, interdisciplinary undergraduate journal, whose mission is to promote high quality research and scholarship among undergraduates by showcasing exemplary work.

- Submissions can be in any basic or applied field of study, including the physical and life sciences, the social sciences, the humanities, education, engineering, and the arts.

- Publication in Aletheia will recognize students who excel academically and foster mentor/mentee relationships between faculty and students.

- In keeping with the strong tradition of student involvement in all levels of Alpha Chi, the journal will also provide a forum for students to become actively involved in the writing, peer review, and publication process.

- More information can be found at www.alphachihonor.org/aletheia. Questions to the editors may be directed to tlindblom@alphachihonor.org or kvosevich@alphachihonor.org.

Alpha Chi National College Honor Society invites to membership juniors, seniors, and graduate students from all disciplines in the top ten percent of their classes. Active on nearly 300 campuses nationwide, chapters induct approximately 10,000 students annually. Since the Society's founding in 1922, Alpha Chi members have dedicated themselves to "making scholarship effective for good." Alpha Chi is a member in good standing of the Association of College Honor Societies, the only national accrediting body for collegiate honor societies. A college seeking a chapter must grant baccalaureate degrees, be regionally accredited, and be a not for profit institution. 
Article Title: Monolingual and Bilingual College Students' Performance on English and Artificial Stroop Tests DOI: $10.21081 / \mathrm{ax} 0306$

ISSN: $2381-800 \mathrm{X}$

This work is licensed under a Creative Commons Attribution 4.0 International License.

\title{
Monolingual and Bilingual College Students' Performance on English and Artificial Stroop Tests
}

\author{
Elise N. Gray \\ Texas Lutheran University \\ Texas Alpha Delta Chapter
}

\begin{abstract}
Problem. Numerous studies have found that bilingual individuals have a cognitive advantage in executive functions compared to monolingual individuals, possibly due to bilinguals' experience with switching between languages and having to inhibit the language that is not in use. This so-called "bilingual cognitive advantage" has been found in task switching, inhibition, monitoring, attention, and conflict resolution (Blumfeld \& Marian, 2014; Donnelly et al., 2019; Gunnerud et al., 2020; Hartanto \& Yang 2019; Stasenko et al., 2017). However, the bilingual cognitive advantage remains controversial as other studies have found no difference in monolinguals and bilinguals (Donnelly et al., 2019), or suggest that differences are task-specific (Blumfeld \& Marian, 2014; Hilbert, 2014) or age-specific and primarily seen in younger children and older adults (Rey-Mermet \& Gade, 2018). The present study seeks to provide insight on this by examining monolingual and bilingual college students' executive functions using English and artificial Stroop tests (Blumfeld \& Marian, 2014; Gunnerud et al., 2020). The traditional Stroop Color Word Test (Hilbert, 2014; Redding \& Gerjets, 1977) requires inhibitory control to say the color of the ink as opposed to the written color word. This may be extra challenging when the words are novel, as was the case for our artificial Stroop test. Given that these tasks require inhibitory control, and bilinguals often have greater inhibitory control than monolinguals, we hypothesized that bilinguals would outperform monolinguals on both Stroop tests.
\end{abstract}

Method. A total of 62 college students (32 monolingual, 30 bilingual) participated in the study. Participants first completed a consent form and a self-reported language proficiency questionnaire (LEAP-Q; Marian, 2007). A control Stroop test was administered, followed by an English Stroop test, then an artificial learning period where participants learned eight artificial color names to $100 \%$ accuracy, and finally an artificial Stroop test. Accuracy, response times, and different scores were calculated for each Stroop test (English congruent, English incongruent, artificial congruent, artificial incongruent).

Results. Data was analyzed in JASP using mixed repeated measures ANOVA with the between-subject factor of language status (monolingual, bilingual), within subject factor of Stroop test (English congruent, English incongruent, artificial congruent, and artificial incongruent), and dependent variables of response time, accuracy, and difference score (incongruent scores congruent scores) for each of the four Stroop tests. Preliminary results revealed a significant main effect of test $(F(3,165)=253.303, p<.001)$ and an interaction of test by language status $(F(3,165)=4.196, p=.007)$. Post-hoc paired sample $t$-tests were used to compare test means. A second one-way repeated measures ANOVA was run with accuracy as a dependent variable revealing a significant main effect of test $(F(3,165)=22.678, p<.001)$, but no between group differences $(F(1,55)=0.039, p=.843)$.

Conclusions. As expected, participants were slower on incongruent than congruent tests and slower on the artificial Stroop tests than the English Stroop tests. Surprisingly, no bilingual advantage was found. In fact, the artificial incongruent test seemed more taxing for bilinguals than monolinguals. Future studies should continue to investigate which tasks would differ between monolinguals and bilinguals and how individuals' language background might influence their cognition.

Keywords: Bilingual cognitive advantage, inhibition, Stroop effect, language learning, and multilingualism 
Language learning begins in infancy and continues to develop each year, even into adulthood (Kuhl et al., 2003). While researching native language acquisition and related skills, researchers have begun to study foreign-language learning with what is called novel-word learning paradigms (Geukes et al., 2015). Altarriba and Mathis, (1997), used pseudowords instead of existing words in their study to avoid any phonological/ orthographic overlap. While conducting their literature review, Geukes et al. (2015), found that Altarriba and Mathis, (1997), was the only word-learning study that used the Stroop test to assess newly learned associations between unfamiliar words and color concepts. The Stroop Color and Word Test is a cognitive test used to measure inhibition that occurs when processing a color word written in an incongruent font color (Stroop, 1935). The individual's accuracy and response time is recorded and used for analysis.

Individuals can acquire multiple languages simultaneously from birth (BFLA: bilingual first language acquisition; Houwer, 2009; Kuhl et al., 2003) or can acquire new non-native languages later in life (SLA: second language acquisition; Klein, 1988; Kuhl et al., 2003). This unique quality of the brain has led some to believe that bilingual and multilingual individuals have a cognitive advantage when compared to monolinguals. For example, Gunnerud et al. (2020), found that bilingual children have an advantage in executive functions which are mental processes that assist in cognitive control abilities such as attention, planning, thinking, and working memory. This observation was reached by having children complete a variety of inhibition tests alongside monolingual children. They found that the bilingual children had a slight advantage in task-switching and attentional inhibition. Despite this supposed advantage, Gunnerud et al. (2020), indicated that evidence supporting a bilingual advantage has not been very consistent regardless of the population tested. It also mentioned how previous studies have had varied results; therefore, more research in this field should be conducted.

Looking closely at bilingual advantages that have been established, Gunnerud et al. (2020), hypothesized that bilingual advantages could be due to neuroplasticity and an increase in age. On the other hand, Yu and Schwieter, (2018), hypothesized that bilingual advantages could be attributed to conflict management and resolution while both languages are being utilized. Other studies have highlighted the following advantages: enhanced executive function, task-switching, faster reaction times, inhibitory control, monitoring, superior adaptability, better job opportunities, and respect of cultures other than one's own (Donnelly et al., 2019; Gunnerud et al., 2020; Hartanto \& Yang 2019; Stasenko et al., 2017). The current study focused on the advantages involving inhibitory control and reaction time.

There are multiple tests and assessments that researchers can use depending on what they intend to study. Bilinguals and multilinguals must code-switch and exercise inhibitory control to successfully communicate with individuals who speak only one or some of their language(s). Task-switching and inhibition tasks are typically used in bilingual and multilingual research (Gunnerud et al., 2020). The demands of such tasks often compete with one another, making it difficult to complete them. This is known as "interference," which can be caused by task materials being incongruent. An incongruent example would be the Stroop test. During this test, individuals must say the word, which is a color, out loud. However, the font color of the words does not match the word that is presented. For a verbal Stroop test, Redding and Gerjets, (1977), noted that the discrepancy between the color that the word is written in and the color denoted by the meaning of the word itself makes it difficult to quickly and accurately identify the color that the word is written in. This is due to what they termed "response competition," which is a form of interference. The Stroop test would likely be more challenging for individuals who do not have significant experience with code-switching or inhibitory control.

The Stroop test was selected over other inhibitory control tasks such as the Simon test because Blumfeld and Marian, (2014), found that bilingual individuals, compared to monolingual individuals, performed better on the Stroop test than the Simon test. Both groups were slower on the incongruent trials and had faster response times on the Stroop test. While Blumfeld and Marian, (2014), found that there was a performance advantage across various cognitive tests, Donnelly et al. (2019), contradictorily determined that there is weak evidence for a bilingual advantage on interference-control tests. Again, due to the varying results, this emphasizes the strong need for more research to be completed in this field (Hartanto \& Yang, 2019).

Several studies have addressed the topic of bilingualism (Blumfeld \& Marian, 2014; Desjardins, 2018; Donnelly et al., 2019; Gunnerud et al., 2020; Hartan- 
to \& Yang 2019; Stasenko et al., 2017; Yu \& Schwieter, 2018); however, because this topic has such diverse findings, there are still many facets to study. A common goal of previous studies was to establish distinct and important differences between bilingual and monolingual individuals through the use of different attention and inhibition tests.

The current research wants to strengthen the claim that bilingual individuals have a cognitive advantage in executive function compared to monolingual individuals (Blumfeld \& Marian, 2014; Gunnerud et al., 2020). This claim will be explored by using an English (Altarriba \& Mathis, 1997; Blumfeld \& Marian, 2014; Rey-Mermet \& Gade 2018; Stasenko et al., 2017) and an artificial Stroop test (Geukes et al., 2015). Donnelly et al. (2019), deems the Stroop test credible for testing for a cognitive advantage, and Geukes et al. (2015), provided support for why artificial words should be used instead of a foreign language. Geukes et al. (2015) found that if novel/artificial words were used, external influences would be better controlled because there would be no overlap between the novel and native language words. This means that fewer confounding variables would affect the results.

For this study, the experimental group consisted of English-Spanish or Spanish-English bilinguals, and the control group consisted of English monolinguals (Altarriba \& Mathis, 1997; Stasenko et al., 2017). The variables measured on both the English and artificial Stroop tests (Altarriba \& Mathis, 1997; Rey-Mermet $\&$ Gade, 2018) were response time and accuracy. In addition, efficiency scores, difference scores, and the amount of time participants took on the learning period were calculated. An efficiency score combines the two dependent variables by dividing reaction time by accuracy (see Blumfeld \& Marian, 2014). A difference score demonstrates the difference in response times between the congruent and incongruent Stroop tests. In addition to the variables being analyzed, participants completed a self-reported language proficiency questionnaire (LEAP-Q; Marian, 2007) to measure their language proficiency, background, and experience (Blumfeld \& Marian, 2014; Donnelly et al., 2019; Yu \& Schwieter, 2018).

In the interim between the two Stroop tests, participants completed a learning period to learn eight artificial words that represented colors (Altarriba \& Mathis, 1997; Geukes et al., 2015). Artificial words were paired with native language (English) words similar to Geukes et al. (2015). Participants took a verbal recall test until all the words were learned as was modeled in Altarriba and Mathis, (1997), which had participants take a series of five quizzes during the learning period. By incorporating a learning period into the study, the researchers were hopeful that reading a novel word would co-activate its recently-learned color-association automatically (Geukes et al., 2015).

Based on previous studies and literature discussed, it was hypothesized that on both the English and the artificial Stroop tests, bilingual individuals would have a faster response time, higher accuracy, and fewer learning periods because of a bilingual cognitive advantage.

\section{Method}

\section{Participants}

Participants included 62 monolingual $(n=32)$ and bilingual $(n=30)$ college students between the ages of 18-25. There were 40 female participants ( 13 bilingual) and 22 male participants (17 bilingual). Of the 30 bilingual participants, 24 were English-Spanish bilinguals and six were Spanish-English bilinguals. Bilingual participants' language proficiency was based on self-report on the LEAP-Q test. Participants were volunteers that were recruited from Texas Lutheran University, as well as other universities by word of mouth. For participating, participants received extra credit in one of their psychology courses. There were five participants omitted from the analysis (four monolingual and one bilingual) because they took more than four times to complete the learning period.

\section{Materials}

Each participant was provided a link to a consent form (found in Appendix A) and a LEAP-Q questionnaire prior to their trial. Each participant was also required to have a computer with internet access for their trial to be conducted virtually. The experimenters conducting the trial required a computer with internet access as well as having the three slideshows prepared for the participants (English Stroop test, artificial Learning Period, and artificial Stroop test) (Stroop tests found in Appendix B and C). Aside from the principal investigator, three other experimenters were needed to run the trials. The three experimenters selected were identified as 
experimenter one, experimenter two, and experimenter three. The principal investigator and experimenters two and three were female; experimenter one was male. All experimenters were in their early 20 s.

\section{Procedure}

Each trial had the same procedures and was not conducted in any intentional order based on participants' schedules. The trials were conducted virtually using Zoom with the participant and one of the four experimenters. Before each trial began, the participants were provided a link to the consent form and the LEAP-Q questionnaire. After confirming completion of these documents, the experimenter began audio and video recordings of the trial for later analysis. The participants were first informed on how the trial would be conducted (reference Appendix D for the experimenter's script). Once the participants understood what they were going to be doing, they were administered a control congruent English Stroop test. It contained eight colors (Red, Yellow, Blue, Green, Orange, Pink, White, and Brown). All 25 words on the control test were congruent; for example, blue was in the font color blue. For all tests, the participants verbally responded to the experimenter by saying the font color of the word, not the actual word. For each test the participants completed, the experimenter recorded response time, accuracy, efficiency, difference scores, and the amount of learning periods. They were then administered the incongruent English Stroop test. It contained the same eight colors as the previous test, but all 25 words were incongruent; for example, blue was in the font color red.

Participants then completed a learning period to learn the artificial language. Experimenters reviewed a PowerPoint with the participants that went through the artificial translations of eight English colors that were found using the Novel Object and Unusual Name database (artificial words found in Appendix E). The artificial words were read aloud to the participants and then they were asked to repeat them. After all of the words were taught to the participants, the experimenter administered a verbal recall test to ensure the participants knew the artificial words. Participants repeated this sequence until they achieved a $100 \%$ completion on the verbal recall test or until they repeated the process four times.

After the learning period, participants were administered the congruent artificial Stroop test. It contained eight colors (Dite, Eder, Fisp, Koba, Jang, Tunk, Stad, and Lorp). All 25 words were congruent; for example, fisp was in the font color fisp. Participants were then administered the incongruent artificial Stroop test. It contained the same eight colors, and all 25 words were incongruent; for example, fisp was in the font color dite. Upon completion of the artificial Stroop test, participants were debriefed by the experimenter.

\section{Research Design}

This was a quasi-experimental design with pre-existing groups of monolingual and bilingual participants. During their experimental session, each participant completed four Stroop tests: English congruent, English incongruent, artificial congruent, and artificial incongruent. Once all data were collected, JASP (JASP Team, 2020) was utilized for data clean-up and analyses.

\section{Results}

All data were analyzed in JASP using a mixed design one-way repeated measures ANOVA with the between-subject factor of language status (monolingual, bilingual), within-subject factor of Stroop test (English congruent, English incongruent, artificial congruent, and artificial incongruent), and dependent variables of response time, accuracy, and difference score (incongruent scores-congruent scores). Post-hoc paired sample $t$-tests were also used to compare group means in the four Stroop tests.

Table 1. and Table 2. below show the mean and standard deviation of each dependent variable that was analyzed within the bilingual and monolingual trials. These dependent variables included response time, accuracy, and difference scores with language status (bilingual or monolingual) representing the independent variable. Response time and accuracy were analyzed four times within each trial (one time per Stroop test), and the difference scores were calculated by using the response times. Inferential statistics were performed on the bilingual $(n=29)$ and monolingual $(n=28)$ participants' data $(N=57)$. There were five participants that took five or more attempts on the learning period and their data was excluded from analysis. 
Table 1

Bilingual Participant Variables (Mean and Standard Deviation Totals per Stroop test)

\begin{tabular}{|c|c|c|c|c|}
\hline & $\begin{array}{c}\text { Congruent English } \\
\text { Stroop }\end{array}$ & $\begin{array}{c}\text { Incongruent English } \\
\text { Stroop }\end{array}$ & $\begin{array}{c}\text { Congruent Artificial } \\
\text { Stroop }\end{array}$ & $\begin{array}{c}\text { Incongruent Artificial } \\
\text { Stroop }\end{array}$ \\
\hline Response Time & $12.252(5.93)$ & $22.621(7.645)$ & $16.977(8.734)$ & $55.245(17.31)$ \\
\hline Accuracy & $1.00(0.00)$ & $0.986(0.034)$ & $1.00(0.00)$ & $0.964(0.054)$ \\
\hline Difference Score & \multicolumn{2}{|c|}{$10.369(8.038)$} & $38.269(16.785)$ \\
\hline
\end{tabular}

Table 2

Monolingual Participant Variables (Mean and Standard Deviation Totals per Stroop test)

\begin{tabular}{|c|c|c|c|c|}
\hline & $\begin{array}{c}\text { Congruent English } \\
\text { Stroop }\end{array}$ & $\begin{array}{c}\text { Incongruent English } \\
\text { Stroop }\end{array}$ & $\begin{array}{c}\text { Congruent Artificial } \\
\text { Stroop }\end{array}$ & $\begin{array}{c}\text { Incongruent Artificial } \\
\text { Stroop }\end{array}$ \\
\hline Response Time & $13.656(4.379)$ & $20.151(4.021)$ & $16.811(4.68)$ & $46.541(14.804)$ \\
\hline Accuracy & $1.00(0.00)$ & $0.991(0.017)$ & $1.00(0.00)$ & $0.956(0.054)$ \\
\hline Difference Score & \multicolumn{2}{|c|}{$6.495(3.565)$} & & $29.73(14.761)$ \\
\hline
\end{tabular}

After in-depth analyses that included three one-way repeated measures ANOVAs that compared bilingual individuals to monolingual individuals were performed on the dependent variables of Response Time, Accuracy, and Difference Score, it was concluded that particular differences indicated as statistically significant met at least the $\alpha=.05$ criterion. For response time, there was a significant main effect of test, $F(3,165)$ $=253.303, p<.001$, and an interaction of test by language status, $F(3,165)=4.196, p=.007$. For accuracy, there was a significant main effect of test, $F(3,165)=22.678, p<.001$, and there was a significant main effect of difference scores, $F(1,55)=169.027, p<.001$. There was also a significant main effect between subjects in regard to difference scores, $F(1,55)=6.12, p=0.016$. There was no between group differences for response time and accuracy variables. Post-hoc paired sample $t$-tests were used to compare response time and accuracy means, and a post-hoc independent sample $t$-test was used to compare difference score means. A one-way ANOVA was also run for the learning period and there was no statistical significance found.

\section{Table 3}

Condensed repeated measures ANOVAs F and p Values

\begin{tabular}{|l|c|c|}
\hline \multicolumn{1}{|c|}{ Dependent Variable } & $F$ & $p$ \\
\hline Response Time & 253.303 & $<.001$ \\
\hline Response Time * LangStatus & 4.196 & 0.007 \\
\hline Accuracy & 22.678 & $<.001$ \\
\hline Difference Score & 169.027 & $<.001$ \\
\hline Difference Score Lang Status & 6.120 & 0.016 \\
\hline
\end{tabular}




\section{Figure 1}

Monolingual vs. Bilingual Response Times on Stroop Tests

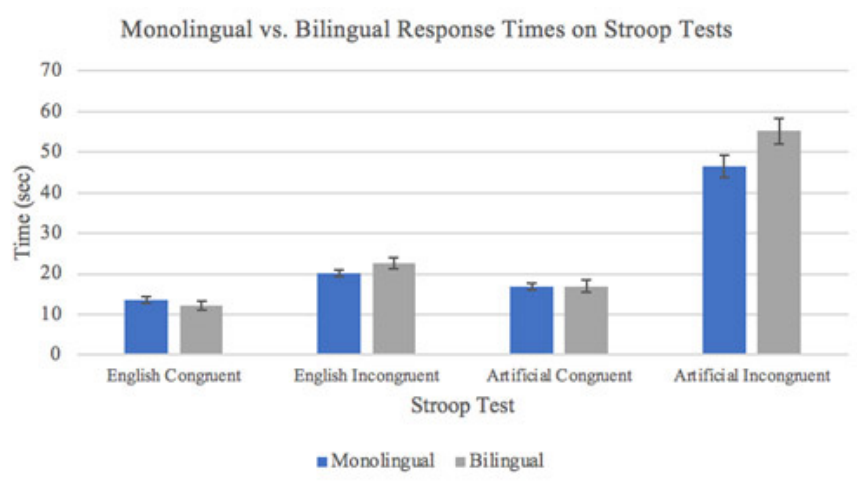

For the dependent variable of response time, results revealed a significant main effect of test $(F(3,165)$ $=253.303, p<.001)$ and an interaction of test by language status $(F(3,165)=4.196, p=.007)$. There was no main effect of language status $(F(1,55)=2.203, p=$ .161) Post-hoc paired sample $t$-tests were used to compare group means in the four Stroop tests. For monolingual and bilingual participants, the artificial incongruent test had the longest response time compared to the other three tests, with the monolinguals having faster response time than bilinguals for the artificial incongruent test.

\section{Figure 2}

Monolingual vs. Bilingual Accuracy on Stroop Tests

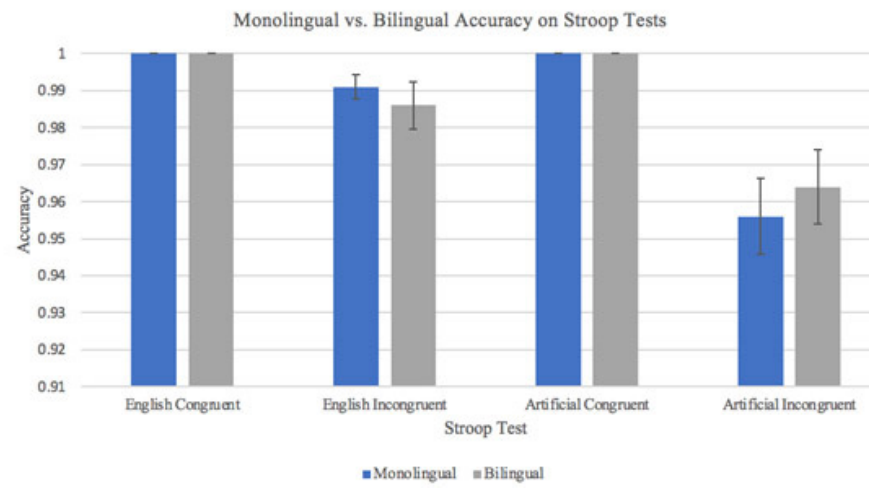

For the dependent variable of accuracy, results revealed a significant main effect of test $(F(3,165)=$ $22.678, p<.001)$, no main effect of language status $(F(1,55)=0.039, p=.843)$, and no interaction of test by language status. Post-hoc paired sample $t$-tests were used to compare group means in the four Stroop tests. The artificial incongruent test had the lowest accuracy scores for both monolingual and bilingual participants.

\section{Figure 3}

Monolingual vs. Bilingual Difference Scores on Stroop Tests

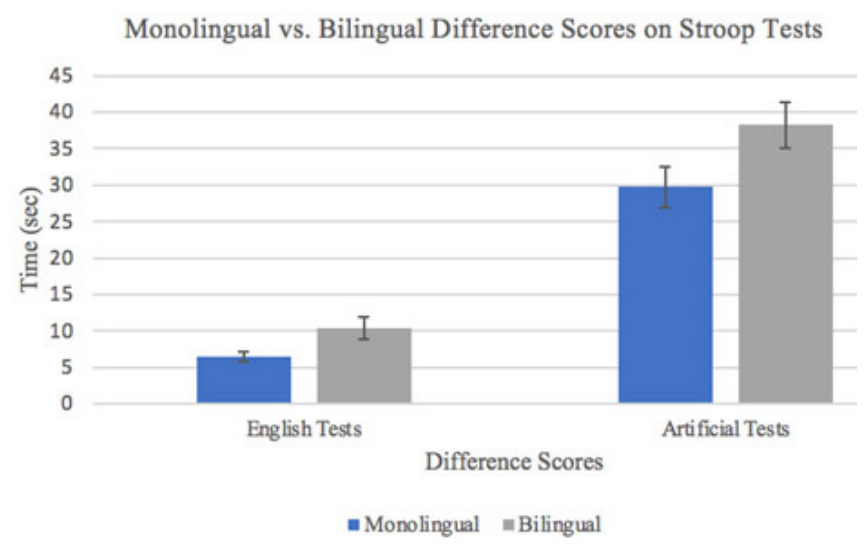

For the dependent variable of response time difference score, results revealed a significant main effect of test $(F(1,55)=169.027, p<.001)$, a significant main effect of language status $(\mathrm{F}(1,55)=6.12, p=0.016)$, but no interaction of test by language status. Post-hoc paired sample $t$-tests were used to compare group means in the four Stroop tests. Participants had longer reaction times for the artificial Stroop tests, both congruent and incongruent, compared to the English Stroop tests.

\section{Discussion}

The current research was conducted due to the varying results found within the literature. Some studies supported a bilingual cognitive advantage (Blumfeld \& Marian, 2014; Stasenko et al., 2017) while others did not (Donnelly et al., 2019; Gunnerud et al., 2020). Blumfeld and Marian, (2014), might have had differing results because, in addition to the Stroop test, they also used the Simon test with both their monolingual and bilingual participants. Furthermore, Gunnerud et al. (2020), might have had differing results because they researched whether there was a bilingual advantage in the executive function of children eighteen years and younger, while this study focused on college-age subjects (18-25). The results from this study do not support the notion that there is a bilingual cognitive advantage (Desjardins, 2018; Donnelly et al., 2019); however, there is a slight monolingual cognitive advantage. It was hypothesized that on both the English and the artificial Stroop test, bilingual individuals would have a faster response time, higher accuracy, and fewer learning periods because of a bilingual cognitive advantage. The similar results from Donnelly et al. (2019), could have resulted from 
the bilingual group being split into both early and late bilinguals; however, the current research study had only early bilinguals. The age of acquisition regarding the participants' language is important because Donnelly et al. (2019), found that it contributed to their participants' results.

Results were not as expected, possibly because bilinguals have an extra cognitive load by already knowing two languages, therefore requiring even greater inhibition for the third language on the artificial Stroop test. In addition, the specific language background of participants (e.g. proficiency level, age of acquisition) may influence whether a bilingual advantage is found or not. All our participants were currently living in south Texas and were early bilinguals, having learned both languages before the age of six. Twenty-four of our participants were English-Spanish bilinguals and six were Spanish-English bilinguals.

After analyzing three one-way repeated measured ANOVAs that compared bilingual individuals to monolingual individuals on the dependent variables of Response Time, Accuracy, and Difference Scores, it was concluded that participants were slower on incongruent (Blumfeld \& Marian, 2014; Hilbert et al., 2014) and artificial Stroop tests compared to the congruent and English Stroop tests. The artificial incongruent Stroop test was the hardest test for bilingual participants (Desjardins, 2018; Donnelly et al., 2019).

\section{Limitations}

This research, although intuitive and informative, still had some limitations. One limitation was that each participant learned the artificial words from a different experimenter. The participants should have instead listened to a pre-recorded audio file recorded by one experimenter; this would help in controlling extraneous variables. Another limitation could have been that the time the participants had between the learning period and the artificial Stroop test was too short. The participants had to be tested right after they learned the artificial words due to the brief time the team had to conduct and collect research. The final limitation was the platform in which the trials were conducted. Due to the 2020 pandemic, all trials had to be conducted via Zoom instead of in person.

\section{Future Studies}

There are many future studies that can be completed in light of this research. This exact trial could be conducted using different languages, independent variables, Stroop tests, or age. This study could also be replicated with other inhibition and attention tasks such as the Flanker, Global-local, Go/no- go, Stop-signal, and the Simon test. Finally, future studies could have the participants learn more than eight words, as well as test them at different periods besides just after learning them. Future studies have a lot of potential and are an exciting advancement in the future and development of language.

\section{Implications}

Take-home messages from this experiment include: 1) bilingual and monolingual participants, on average, did not differ in how fast or accurate they were in the experiment except in difference scores, 2) presenting participants with unfamiliar words resulted in both groups learning them, on average, at the same rate, and 3) understanding that the supposed bilingual cognitive advantage was not shown in this study. Although the Stroop test is used in experimental contexts and may not have clear implications for real world settings, the cognitive processes it measures are highly relevant for many other contexts. For example, cognitive inhibition is necessary in the college classroom for students to be able to ignore distractions (e.g. classmates talking, external environmental noises, cell phone notifications) and focus on relevant information (e.g. lecture, assignment instructions). This cognitive ability is essential for all students regardless whether they are monolingual or bilingual. However, it is important to keep in mind that bilinguals may have additional processing demands for tasks that require extra inhibition. 


\section{References}

Altarriba, J., \& Mathis, K. M. (1997). Conceptual and lexical development in second language acquisition. Journal of Memory and Language, 36(4), 550-568. https://doi-org.ezproxy.tlu.edu/10.1006/ jmla.1997.2493

Blumenfeld, H. K., \& Marian, V. (2014). Cognitive control in bilinguals: Advantages in Stimulus-Stimulus inhibition. Bilingualism: Language and Cognition, 17(3), 610-629. https://doi-org.ezproxy.tlu. $\mathrm{edu} / 10.1017 / \mathrm{S} 1366728913000564$

Desjardins, J. L., \& Fernandez, F. (2018). Performance on auditory and visual tests of inhibition in English monolingual and Spanish-English bilingual adults: Do bilinguals have a cognitive advantage? Journal of Speech, Language, and Hearing Research, 61(2), 410-419. https://doi-org.ezproxy.tlu. edu/10.1044/2017 JSLHR-H-17-0160

Donnelly, S., Brooks, P. J., \& Homer, B. D. (2019). Is there a bilingual advantage on interference-control tasks? A multiverse meta-analysis of global reaction time and interference cost. Psychonomic Bulletin \& Review, 26(4), 1122-1147.https://doi-org.ezproxy. tlu.edu/10.3758/s13423-019-01567-z

Geukes, S., Gaskell, M. G., \& Zwitserlood, P. (2015). Stroop effects from newly learned color words: effects of memory consolidation and episodic context. Frontiers in psychology, 6, 278. https://doi. org/10.3389/fpsyg.2015.00278

Gunnerud, H. L., ten Braak, D., Reikerås, E. K. L., Donolato, E., \& Melby-Lervåg, M. (2020). Is bilingualism related to a cognitive advantage in children? A systematic review and meta-analysis. Psychological Bulletin. https://doi-org.ezproxy.tlu.edu/10.1037/ bul0000301

Hartanto, A., \& Yang, H. (2019). Does early active bilingualism enhance inhibitory control and monitoring? A propensity-matching analysis. Journal of Experimental Psychology: Learning, Memory, and Cognition, 45(2), 360-378. https://doi-org.ezproxy.tlu. edu/10.1037/xlm0000581

Hilbert, S., Nakagawa, T. T., Bindl, M., \& Bühner, M. (2014). The spatial Stroop effect: A comparison of color-word and position-word interference. Psychonomic Bulletin \& Review, 21(6), 1509-1515. https://doi-org.ezproxy.tlu.edu/10.3758/s13423014-0631-4
Houwer, A. (2009). Bilingual First Language Acquisition. Bristol, Blue Ridge Summit: Multilingual Matters. https://doi.org/10.21832/9781847691507

JASP Team (2020). JASP (Version 0.14.1)[Computer software].

Klein, W. (1988). Second Language Acquisition. International Encyclopedia of the Social \& Behavioral Sciences. 10.2307/414588.

Kuhl, P., Tsao, F., and Liu, H. (2003). Foreign-language experience in infancy: Effects of short-term exposure and social interaction on phonetic learning. PNAS. 100 (15) 9096-9101; https://doi.org/10.1073/ pnas. 1532872100

Marian, V., Blumenfeld, H. K., \& Kaushanskaya, M. (2007). The language experience and proficiency questionnaire (LEAP-Q): Assessing language profiles in bilinguals and multilinguals. Journal of Speech, Language, and Hearing Research, 50(4), 940-967. https://doi-org.ezproxy.tlu. edu/10.1044/1092-4388(2007/067)(2018). Multilingual people. Ilanguages.org http://ilanguages.org/ bilingual.php

Rey-Mermet, A., \& Gade, M. (2018). Inhibition in aging: What is preserved? What declines? A meta-analysis. Psychonomic Bulletin \& Review, 25(5), 1695 1716. https://doi-org.ezproxy.tlu.edu/10.3758/ s13423-017-1384-7

Redding, G. M., \& Gerjets, D. A. (1977). Stroop effect: interference and facilitation with verbal and manual responses. Perceptual and motor skills, 45(1), 1117. https://doi.org/10.2466/pms.1977.45.1.11

Stasenko, A., Matt, G. E., \& Gollan, T. H. (2017). A relative bilingual advantage in switching with preparation: Nuanced explorations of the proposed association between bilingualism and task switching. Journal of Experimental Psychology: General, 146(11), 1527-1550. https://doi-org.ezproxy.tlu. edu/10.1037/xge0000340.supp (Supplemental)

Stroop J. R. (1935). Studies of interference in serial verbal reactions. J. Exp. Psychol. 18, 643-662. 10.1037/ h0054651

Yu, Z., \& Schwieter, J. W. (2018). Recognizing the effects of language mode on the cognitive advantages of bilingualism. Frontiers in Psychology, 9. https:// doi-org.ezproxy.tlu.edu/10.3389/fpsyg.2018.00366 


\section{Appendix A: Statement of Consent}

I consent to participate in this research experiment. This experiment will involve taking four Stroop tests and participating in a learning session. I consent to taking the four Stroop Tests and participating in a learning session. This will be followed by a debriefing session.

Trial length will range from 30 minutes to 1 hour depending on response time and learning period time.

Personal information will be kept confidential by assigning number codes to each participant to keep identities anonymous. All personal information collected will be separate from the consent forms to ensure confidentiality. The only people with access to these records are the primary researcher, faculty sponsor, and research assistants.

You have the ability to withdraw at any point of the experiment. Additionally, you can refuse to participate. You do not need a reason for refusal or withdrawal, and you will not be penalized for doing so. Should you choose to participate, you must not discuss this experiment with other participants and people not involved with the experiment as to maintain the integrity of this research.

Expected benefits of study are to further support the literature on bilingual cognitive advantage, as well as explore how multiple layers of inhibition affect inhibition control. The latter is important because there has been very little research on the effects of multiple layers of inhibition between monolingual and bilingual individuals.

Questions regarding research and subjects' rights can be directed towards the research assistants or the faculty sponsor, Dr. Woods:

Dr. Elizabeth Woods, Faculty Sponsor

Department of Psychology

ewoods@tlu.edu

(830) 372-6341

Elise Gray, Principle Investigator

Participant's Name: Date Signed:

Participant's Signature: $\quad$ Email: 


\section{Appendix B: English Stroop Tests}

Pronounce the font color upon instruction: Red Blue Yellow Pink Orange Blue Green Blue Green Yellow Orange Blue White Brown Red Blue Yellow Green Pink Yellow Green Blue Red

Pronounce the font color upon instruction:

Red Green Blue Yellow Pink

Orange Blue Pink Brown White

Green Yellow Orange Blue White

Brown Red White Yellow Green

Pink Yellow Brown Orange Red 
$\underline{\text { Appendix C: Artificial Stroop Tests }}$

Pronounce the color of the word (not the word) upon instruction:

Dite

Tunk

Lorp

Koba

Eder

Jang

Dite

Tunk

Fisp

Stad

Lorp

Eder

Dite

Koba

Dite

Eder

Stad

Lorp

Jang

Fisp

Koba

Tunk

Pronounce the word upon instruction:

Dite

Tunk

Stad

Lorp

Koba

Eder

Jang

Dite

Fisp

Tunk

Fisp

Stad

Lorp

Eder

Dite

Koba

Dite

Eder

Stad

Lorp

Jang

Fisp

Koba

Tunk

Jang 


\section{Appendix D: Experimenter's Script}

\section{Introduction:}

Make sure the consent form and LEAP-Q test are completed prior to zoom.

*If they are color blind* "The English Stroop test is focused around identifying colors, so you have the option to leave at any time if you find this too difficult. If you would like to go forth in this study, we will continue!"

"Today you will be completing two separate activities that focus on English and foreign words. In between the first and second activity, there will be a break to learn the foreign words."

Pull up English Stroop Test (in presentation mode):

"This is an example for how the words in the first activity will look. In the first part of this activity, the font color will match the word. For the second part of this activity the font color will not match the word. For both parts of this activity you will be saying the color of the font. Questions? When you are ready please say the font color from left to right."

After they complete the example slides say:

"We will now start the first activity. You will be reading from left to right, starting at the top left just like you would read a page in a book. There are 25 words. The font color matches the word. Please read the font color. If you make a mistake on a word don't try to correct it. Just keep going. When I switch to the first activity, I will tell you when to start. I will be testing for accuracy and completion time so please try to go as fast but as accurately as possible. Questions?"

"Ready, set, go" Begin stopwatch. Take note of which words they miss and stop the stopwatch when they stop speaking.

"We will now move to the second part of the first activity. I will show you the example slides now. Questions?"

"This is an example for how the words in the second part of this activity will look. The font color will not match the word, but you will need to say the font color, not the spelling of the word. For example, if the actual word is "blue" but the font color is "red" you will say "red." If the actual word is "orange" but the font color is "yellow" you will say "yellow". Questions? When you are ready please say the font color from left to right."

After they complete the example slides say:

"We will now start the second part of the first activity. You will be reading from left to right, starting at the top left just like you did on the last activity. There are 25 words. The font color does not match the word. Please read the font color. If you make a mistake on a word don't try to correct it. Just keep going. I will be testing for accurately and completion time so please try to go as fast but as accurate as possible. Questions?"

"Ready, set, go" Begin stopwatch. Take note of which words they miss and stop the stopwatch when they stop speaking. "The first activity is complete. We will now proceed to the learning session. Questions?"

Stop screen sharing, pull up learning period slideshow, resume screen sharing once in presentation mode.

"We will now begin the second part of this trial which is the learning period. I will read you the name of a color in English and then I will tell you the name of the color in the foreign language. For example, I will say "Red in the foreign language is Dite." I will then ask you to repeat the foreign word back to me to make sure you pronounce it correctly. Once we have gone through the 8 colors, I will be testing you to see how many of the words you can remember and get right. This will be a verbal recall test so you will not be able to see the words when being tested. We will repeat this process of going over the words and testing your ability to remember until you get $100 \%$ of the words correct. Please do not take notes or write down anything that will help you."

"Ready? This is the color red. The foreign word for the color red is dite. Can you say dite?"

Conduct learning period until completion OR until four retests occur.

Once learning period is complete, stop screen sharing, pull up artificial test, resume screen sharing once in presentation mode.

Repeat all instructions that were given in the English Stroop Tests.

Stop screen sharing and debrief. 
Appendix E: Artificial words with English translation

\begin{tabular}{|c|c|}
\hline English Word & Artificial Word \\
\hline Red & Dite \\
\hline Yellow & Eder \\
\hline Blue & Fisp \\
\hline Green & Koba \\
\hline Orange & Jang \\
\hline Pink & Tunk \\
\hline White & Stad \\
\hline Brown & Lorp \\
\hline
\end{tabular}

